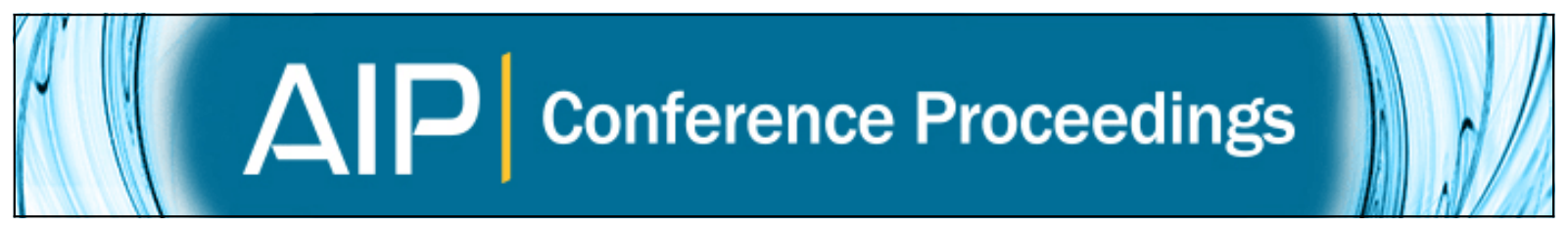

\title{
Characterization of positive clusters in the CLOUD nucleation experiments
}

Federico Bianchi, Jasmin Tröstl, Siegfried Schobesberger, Heikki Junninen, Josef Dommen, Douglas R.

Worsnop, Urs Baltensperger, and CLOUD Collaboration

Citation: AIP Conference Proceedings 1527, 346 (2013); doi: 10.1063/1.4803274

View online: http://dx.doi.org/10.1063/1.4803274

View Table of Contents: http://scitation.aip.org/content/aip/proceeding/aipcp/1527?ver=pdfcov

Published by the AIP Publishing

\section{Articles you may be interested in}

Nucleation of $\mathrm{H} 2$ SO 4 and oxidized organics in CLOUD experiment

AIP Conf. Proc. 1527, 318 (2013); 10.1063/1.4803267

Hygroscopicity of nucleated nanoparticles in CLOUD 7 experiments

AIP Conf. Proc. 1527, 306 (2013); 10.1063/1.4803264

Measuring composition and growth of ion clusters of sulfuric acid, ammonia, amines and oxidized organics as first steps of nucleation in the CLOUD experiment

AIP Conf. Proc. 1527, 298 (2013); 10.1063/1.4803262

Atmospheric nucleation and growth in the CLOUD experiment at CERN

AIP Conf. Proc. 1527, 278 (2013); 10.1063/1.4803258

Generalized theory of nucleation kinetics. IV. Nucleation as diffusion in the space of cluster dimensions, positions, orientations, and internal structure

J. Chem. Phys. 85, 3042 (1986); 10.1063/1.451012 


\title{
Characterization of positive clusters in the CLOUD nucleation experiments
}

\author{
Federico Bianchi ${ }^{\mathrm{a}}$, Jasmin Tröstl ${ }^{\mathrm{a}}$, Siegfried Schobesberger ${ }^{\mathrm{b}}$, Heikki \\ Junninen $^{\mathrm{b}}$, Josef Dommen ${ }^{\mathrm{a}}$, Douglas R. Worsnop ${ }^{\mathrm{b}, \mathrm{c}}$, Urs Baltensperger ${ }^{\mathrm{a}}$ \\ and the CLOUD collaboration.
}

\author{
${ }^{a}$ Laboratory of Atmospheric Chemistry, Paul Scherrer Institute, 5232 Villigen PSI, Switzerland \\ ${ }^{b}$ Department of Physics, University of Helsinki, P.O. Box 64, FI-00014 University of Helsinki, Finland \\ 'Aerodyne Research, Inc., 45 Manning Road, Billerica, MA 01821, USA
}

\begin{abstract}
The mechanism of new particle formation (NPF) events is still poorly understood. The CLOUD experiment is studying at which conditions this process occurs. During the CLOUD 7 campaign (fall 2012) the evolution of the nucleation rate with different reagents (sulphuric acid, ammonia, dimethylamine and $\alpha$-pinene) was tested. Here we investigate the composition of freshly formed positive ions during the nucleation process, which allows us to understand the formation mechanisms of these clusters. The time evolution of the clusters is shown demonstrating the correlation between the formation of these clusters and the nucleation process.
\end{abstract}

Keywords: clusters, ions, nucleation, mass spectrometry, CLOUD

PACS: 36.40.Wa, 36.40.-c, 34.50.Gb, 82.80.Rt, 82.60.Nh, 82.70.Rr, 92.60.Mt

\section{INTRODUCTION}

Formation of new particles from trace gases (nucleation) is the main source of aerosol in the atmosphere [1]. Once the particles are formed they can grow and some of them reach the size of cloud condensation nuclei $(\mathrm{CCN})$. It has been estimated that nucleation may be responsible for the formation of up to $50 \%$ of the total $\mathrm{CCN}$ concentrations [2]. Despite the importance of the process and the number of studies focusing on this topic, the mechanism of nucleation is still highly uncertain. There is growing evidence that the main precursor of this process is sulphuric acid that is produced by the oxidation of sulphur dioxide. On the other end the CLOUD (Cosmics Leaving OUtdoor Droplets) experiment demonstrated that sulphuric acid alone or together with ammonia cannot explain nucleation and growth rates observed in the planetary boundary layer [3]. Some studies also showed the importance of amines and oxygenated organic compounds in this process $[4,5]$.

To understand the nucleation mechanism it is fundamental to determine which trace species participate in the first steps of the nucleation process. The CLOUD chamber is very well suited to run such experiments. First, there is no other chamber where the concentration of contaminants is similarly low. Second, an unprecedented variety of state-of-the-art instruments are used. The few contaminants that are still present are 
measured with very low detection limits, and the chemical composition of ions smaller than $2 \mathrm{~nm}$ is measured with mass spectrometric techniques.

\section{METHOD}

The CLOUD (Cosmics Leaving OUtdoor Droplets) experiment is based at CERN, Geneva. The core of the experiment is a $26 \mathrm{~m}^{3}$ electropolished stainless-steel chamber, equipped with state-of-the-art instruments in nucleation measurements. The chamber is based at CERN where we can expose it to a $\pi^{+}$beam coming from the proton synchrotron (PS) to simulate the effect of the galactic cosmic rays (GCR) on the new particle formation process. The beam intensity was changed to determine the influence of ions at different altitude. The concentrations of contaminants are minimized to the best possible extent [3]. The temperature can be controlled with a precision of $\pm 0.01 \mathrm{~K}$ and during this set of experiments the temperature were kept constant at $278 \mathrm{~K}$. The relative humidity during CLOUD 7 was also constant and was kept at $38 \%$. The concentrations of sulphuric acid $\left(\mathrm{SA}, \mathrm{H}_{2} \mathrm{SO}_{4}\right)$, ammonia $\left(\mathrm{NH}_{3}\right)$, dimethylamine (DMA, $\left.\left(\mathrm{CH}_{3}\right)_{2} \mathrm{NH}\right)$, and $\alpha$-pinene $\left(\mathrm{C}_{10} \mathrm{H}_{16}\right)$ were varied. The nucleation process was triggered by UV light forming $\mathrm{OH}$ radicals from photolysis reactions with ozone or HONO. These triggered the oxidization of sulphur dioxide and $\alpha$-pinene forming sulphuric acid and oxidized organics (OxOrg), respectively. The instruments were placed around the chamber with 120 -cm long sampling lines. The chamber was continuously refilled with artificial air containing trace gases at a total flow of around $150 \mathrm{~L} / \mathrm{min}$.

The current work aimed at showing the chemical composition of the positive ions during nucleation under different conditions. The chemical composition of these ions was determined using an atmospheric pressure interface time-of-flight mass spectrometer (APi-TOF) run in positive mode [6]. This instrument is able to sample directly the ions through a critical orifice and measure the mass-to-charge ratio accurately enough to determine the chemical composition. The resolution of the APiTOF is higher than $5000 \mathrm{Th} / \mathrm{Th}$ with a mass accuracy better than $10 \mathrm{ppm}$. The mass range for this instrument was from 30 to $1800 \mathrm{Th}$. The instrument is composed of two parts. The first part is the atmospheric pressure interface guiding the ions from the critical orifice to the mass spectrometer. During this stage the pressure decreases from atmospheric pressure to a final pressure of $10^{-6}$ mbar. The second part is a time-offlight mass spectrometer (Tofwerk, Switzerland). The positive clusters measured with this instrument were ionized inside the CLOUD chamber, as there is no ionization process inside the instrument.

\section{RESULTS AND DISCUSSION}

Results of binary homogeneous nucleation $\left(\mathrm{H}_{2} \mathrm{O}\right.$ and $\left.\mathrm{H}_{2} \mathrm{SO}_{4}\right)$ and ternary homogeneous nucleation $\left(\mathrm{H}_{2} \mathrm{O}, \mathrm{H}_{2} \mathrm{SO}_{4}\right.$ and $\left.\mathrm{NH}_{3}\right)$ were published already [3]. Here we present the composition of positive ions for the $\mathrm{H}_{2} \mathrm{SO}_{4}$ - DMA and $\mathrm{H}_{2} \mathrm{SO}_{4}$ - oxidized organics (OxOrg) systems. The results will be compared with the previous results regarding $\mathrm{H}_{2} \mathrm{SO}_{4}-\mathrm{NH}_{3}$ nucleation. 
In the latter case, the positive ions had the composition of: $\left(\mathrm{H}_{2} \mathrm{SO}_{4}\right)_{\mathrm{n}} *\left(\mathrm{NH}_{3}\right)_{\mathrm{n}+1} * \mathrm{H}^{+}$, however, after the cluster reached a certain size one extra molecule of ammonia was found in the cluster. With the presence of DMA ammonia was substituted by DMA but the structure of the composition and the stoichiometry were essentially the same. Figure 1 shows the time evolution of these clusters. It is seen that building blocks of $\left(\mathrm{H}_{2} \mathrm{SO}_{4}\right)\left(\mathrm{C}_{2} \mathrm{H}_{7} \mathrm{~N}\right)$ are added sequentially to the growing clusters.

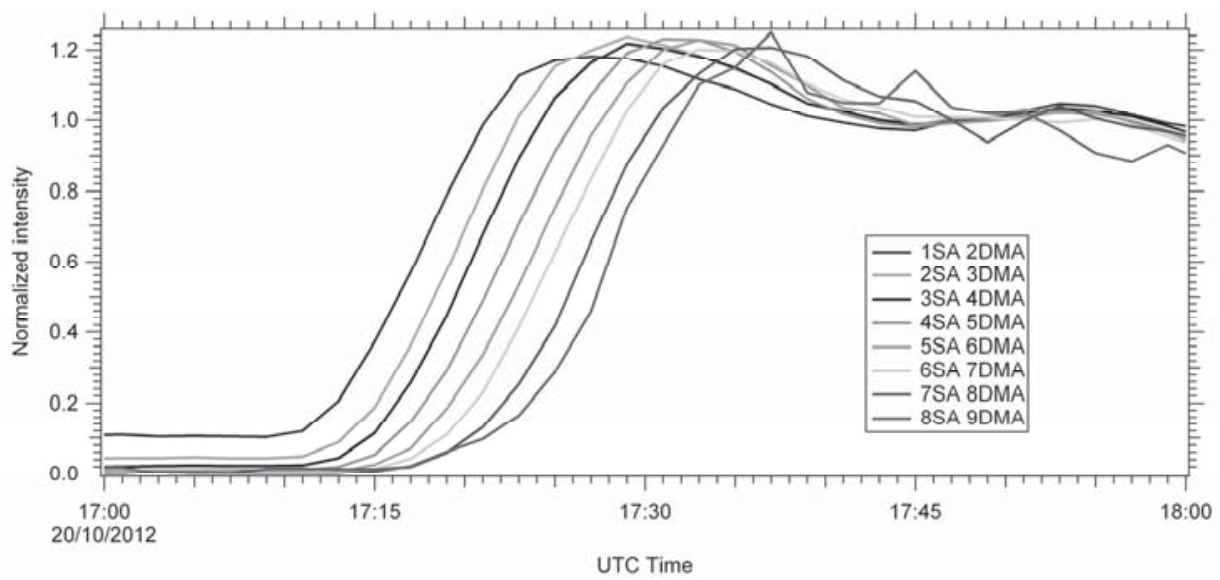

FIGURE 1. Time evolution of positively charged clusters during a $\mathrm{H}_{2} \mathrm{SO}_{4}-\mathrm{C}_{2} \mathrm{H}_{7} \mathrm{~N}$ experiment. The first cluster appearing is composed of one $\mathrm{H}_{2} \mathrm{SO}_{4}$ and two $\mathrm{C}_{2} \mathrm{H}_{7} \mathrm{~N}$ with a positive charge given by a proton. The clusters appearing have additional building blocks composed of one $\mathrm{H}_{2} \mathrm{SO}_{4}$ and one $\mathrm{C}_{2} \mathrm{H}_{7} \mathrm{~N}$.

The time evolution was also investigated with other precursors (i.e. $\mathrm{NH}_{3}$, OxOrg). Even though there is no basic difference in the APi-TOF spectra for the experiments with ammonia and dimethylamine the nucleation and growth rates for the two cases were quite different. With OxOrg the most important clusters were found in an $\mathrm{m} / \mathrm{z}$ range from 200 Th up to $1500 \mathrm{Th}$. Below 200 Th many plausible oxidation products of $\alpha$-pinene were identified, such as Pinonic acid, Pinonaldehyde, whereas some compounds remained unidentified. In all these positively charged clusters no $\mathrm{H}_{2} \mathrm{SO}_{4}$ was observed, as far as the clusters' composition could be identified.

The composition of the positive ions generated during the nucleation and growth process will help in the understanding of the nucleation process and the involved chemical mechanisms. The next step will be to compare these results with the positive ions observed in the ambient atmosphere during nucleation events.

\section{ACKNOWLEDGMENTS}

We would like to thank CERN for supporting CLOUD with important technical and financial resources, and for providing a particle beam from the CERN Proton Synchrotron. This research has received funding from the EC Seventh Framework Programme (Marie Curie Initial Training Network "CLOUD-ITN" no. 215072, MCITN "CLOUD-TRAIN" no. 316662, and ERC-Advanced "ATMNUCLE" grant no. 227463), the German Federal Ministry of Education and Research (project nos. 01LK0902A and 01LK1222A), the Swiss National Science Foundation (project nos. 
200020_135307 and 206620_130527), the Academy of Finland (Center of Excellence project no. 1118615), the Academy of Finland (135054, 133872, 251427, 139656, 139995, 137749, 141217, 141451), the Finnish Funding Agency for Technology and Innovation, the Nessling Foundation, the Austrian Science Fund (FWF; project no. P19546 and L593), the Portuguese Foundation for Science and Technology (project no. CERN/FP/116387/2010), the Swedish Research Council, Vetenskapsrådet (grant 2011-5120), the Presidium of the Russian Academy of Sciences and Russian Foundation for Basic Research (grants 08-02-91006-CERN and 12-02-91522-CERN), and the U.S. National Science Foundation (grants AGS1136479 and CHE1012293).

\section{REFERENCES}

1 - M. Kulmala et al.,. J. Aerosol Sci. 35, 143 - 176 (2004).

2 - J. Merikanto et al., Atmos. Chem. Phys. 9, 8601-8616 (2009).

3 - J. Kirkby et al., Nature 476, 429-433 (2011).

4- A. Metzger et al., Proc. Natl. Acad. Sci. USA 107, 6646-6651 (2010).

5 - B. R. Bzdek et al, Atmos. Chem. Phys., 11, 8735-8743, (2011)

6. H. Junninen et al., Atmos. Meas. Tech. 3(4), 039-1053 (2010). 